\title{
LA ECONOMÍA VENEZOLANA \\ EN EL SIGLO XX
}

PABLO ASTORGA *

Oxford Economic Forecasting

\section{RESUMEN}

Este trabajo estudia el desarrollo económico venezolano desde una perspectiva regional. La riqueza petrolera le ha dado a Venezuela una oportunidad única para ampliar su capacidad productiva y mejorar el bienestar de la población. Sin embargo, el país ha experimentado un deterioro marcado en su economía e instituciones en tiempos recientes. El artículo comienza con una visión comparativa con base en algunos indicadores de bienestar. Luego explora las implicaciones de las bonanzas de los productos de exportación y establece paralelismos con el caso del cobre y el salitre chilenos y el caucho amazónico. A continuación analiza el impacto de la Gran Depresión y el proceso de industrialización. Para terminar, ofrece un conjunto de conclusiones.

\section{ABSTRACT}

This paper studies the process of economic development in Venezuela from a regional perspective. Oil wealth has given the country a unique opportunity to expand its productive capacity and improve the living standards. However, the country has experienced a drastic deterioration of its economy and institutions in recent times. The paper begins with a comparison based on welfare indicators. Then, it explores the economic implications of commodities and establishes parallels with the export booms of copper and nitrate

* Debo mi agradecimiento a Asdrúbal Baptista por su apoyo y a la Fundación Polar por financiar este trabajo. El mismo se ha beneficiado por los comentarios de un evaluador anónimo de la Revista de Historia Económica y por las observaciones de Brian McBeth y Germán Utreras. Begoña Dávila gentilmente editó el manuscrito. 
in Chile and rubber in the Amazon region. Next, it analyses the impact of the Great Depression and the industrialisation strategy. Finally, a set of conclusions is presented.

JEL Classification: N16, N36, N56, O1, O54.

\section{INTRODUCCIÓN}

En 1905, Augusto Ramos, un técnico brasileño del café, visitó Venezuela en una gira por diferentes países productores de la región. Su impresión de las condiciones en que se encontraba el país se resume en un comentario que dejó en un libro que escribió años después sobre sus viajes: «... un país digno de un mejor destino» (Ramos, 1923). A los ojos de este visitante singular, Venezuela mostraba un nivel de atraso respecto a otros lugares que había visitado. Aquéllos eran tiempos difíciles para el país. Reinaba un gran nivel de anarquía e inestabilidad política, y todavía estaba fresco el recuerdo del bloqueo de las potencias acreedoras en 1902 como resultado del incumplimiento en el servicio de la deuda externa. Sin embargo, para lo que seguramente habría sido una grata sorpresa para Ramos, durante los años que siguieron Venezuela experimentó grandes transformaciones. El país del café fue desplazado por el del petróleo, se encontró el camino de la estabilidad política y la nueva fuente de riqueza permitió mejorar considerablemente las condiciones de vida de los venezolanos. Llegados los años setenta, en la cúspide de la bonanza petrolera, se rebosaba optimismo. Pronto esta ilusión llegaría a su fin con la crisis de la deuda y la caída de los precios del petróleo en los años ochenta, dando inicio a una prolongada recesión $y$, eventualmente, a la vuelta a la inestabilidad política.

Dentro del contexto latinoamericano, Venezuela ha sido una excepción en muchos sentidos. País durante muchos años con el mayor producto interno bruto (PIB) e importaciones per cápita, y, a partir de los años cuarenta, con la mayor dependencia fiscal y externa de un solo producto. Además, ha contado con un nivel de inversión extranjera directa sin precedentes en la región ${ }^{1} \mathrm{y}$, hasta tiempos recientes, ha mostrado una tendencia favorable en los términos de intercambio y ausencia de problemas de balanza de pagos e inflación. Sin embargo, la evolución de la economía

' En 1950 el valor en libros de la inversión directa de Estados Unidos en Venezuela era de 1.184 millones de dólares, un 21 por 100 del total de las inversiones directas de ese país en América Latina para ese momento (Naciones Unidas, 1955). 
venezolana también ha estado marcada por problemas y característica comunes, sobre todo con otras economías mineras de la región. Los países presentan similitudes en su historia, instituciones, modelos de desarrollo, características estructurales (p. ej., concentración de exportaciones), exposición a crisis externas y procesos típicos asociados al desarrollo económico (p. ej., urbanización, migración acelerada e industrialización).

El propósito de este artículo es estudiar el proceso de desarrollo venezolano desde una perspectiva histórica y comparada. A tal fin, se seleccionan $\mathrm{y}$ resaltan ciertos hechos e indicadores $\mathrm{y}$ se hacen ciertas comparaciones buscando establecer paralelismos con otros países latinoamericanos. Una discusión de esta naturaleza toca temas básicos de la literatura del desarrollo económico, como son sus regularidades, el papel de los recursos naturales, la importancia de las condiciones iniciales, los cambios institucionales, las políticas económicas adoptadas y las consecuencias de los cambios externos. Estos temas han sido claves en la evolución de los países de la región y están presentes a lo largo de nuestra presentación.

El plan de desarrollo del trabajo es el siguiente. En la sección 2 se presenta una visión comparativa del desarrollo de Venezuela durante el siglo $\mathrm{XX}$ con la ayuda de algunos indicadores cuantitativos sobre bienestar y desempeño económico. La sección 3 explora el tema de las implicaciones de los productos de exportación para el desarrollo económico. Para ello hace uso del concepto de lotería de los recursos naturales y el papel de los encadenamientos directos e indirectos. La sección siguiente discute los efectos de las bonanzas bajo la óptica del modelo del síndrome holandés y presenta las experiencias de la explotación del caucho en la Amazonía y las bonanzas vinculadas con las exportaciones de salitre y cobre en Chile. La sección 5 estudia el impacto de las conmociones externas y su importancia como agentes de cambio, con especial referencia a la Gran Depresión. La sección 6 cubre el proceso de industrialización y la siembra del petróleo en los años sesenta y setenta. Finalmente se ofrecen un conjunto de conclusiones.

\section{COMPARACIÓN GENERAL}

Esta sección presenta una visión general comparativa del desarrollo venezolano en el transcurso del siglo $\mathrm{xx}$ a partir de una serie de indicadores sobre las condiciones de vida y la estructura y desempeño de la economía. El ejercicio de comparar y contrastar la economía venezolana con la de 
Latinoamérica como conjunto presenta ciertas limitaciones debido a la existencia de una gran diversidad en la región que a veces hace difícil generalizar y resta fuerza a la representatividad de los promedios. Esto es sobre todo cierto a comienzos del siglo xx cuando existía una mayor disparidad en los niveles de desarrollo de los países de la región. Así, por ejemplo, mientras Argentina se contaba entre las economías con mayor potencial para unirse al grupo de los países desarrollados, en el extremo opuesto se encontraban países como Guatemala con una esperanza de vida al nacer menor de 25 años y donde el 88 por 100 de la población era analfabeta. Sin embargo, a pesar de estas diferencias, es indudable que hay rasgos comunes que pueden dar sustento a generalizaciones y representatividad a los promedios regionales.

A continuación se compara el desempeño venezolano con el promedio latinoamericano durante cinco momentos del siglo: al inicio (1900), en el momento de la Gran Depresión (1930), a mediados del siglo y primeros años de la posguerra (1950), previo a la crisis de la deuda externa (1980) $y$, finalmente, al cierre del siglo (2000). Los indicadores utilizados son: producto interno bruto per cápita (en dólares a precios de 1970 ajustados por la paridad del poder adquisitivo), esperanza de vida al nacer, tasa de alfabetización de la población mayor de 15 años, tasa de urbanización (medida como el porcentaje de habitantes en centros urbanos de más de 20.000 habitantes), la tasa compuesta anual del crecimiento poblacional, la capacidad importadora (medida como el volumen per cápita de importaciones en dólares a precios de 1970) y el índice de concentración de exportaciones. Este último mide el peso de los dos bienes principales de exportación en el total exportado, donde valores cercanos a 100 indican un nivel extremo de concentración. Los últimos dos indicadores reflejan el grado de apertura de la economía al comercio exterior y su vulnerabilidad ante choques externos.

Los resultados se resumen en el cuadro 1. Cada casilla del cuadro incluye tres valores. En la parte superior se muestra el producto de dividir el valor para Venezuela por el promedio de Latinoamérica, de manera que valores cercanos a la unidad reflejan proximidad respecto al valor típico de la región. En la parte inferior (entre paréntesis) se muestra, en primer lugar, la cifra absoluta para Venezuela y, luego, la del país que registra el valor máximo. Así, por ejemplo, la primera casilla relativa al PIB per cápita cerca de 1900 indica que en ese momento los venezolanos tenían un ingreso de 106 dólares per cápita, equivalente al 57 por 100 del pro- 


\section{CUADRO 1}

Indicadores de desarrollo durante el siglo $\mathrm{XX}$

\begin{tabular}{|c|c|c|c|c|c|}
\hline & 1900 & 1930 & 1950 & 1980 & 2000 \\
\hline $\begin{array}{l}\text { PIB per cápita } \\
(\$ p p a)\end{array}$ & $\begin{array}{c}0,57 \\
\text { (106/Arg.: 439) }\end{array}$ & $\begin{array}{c}1,47 \\
(408 / \operatorname{Arg} .: 559)\end{array}$ & $\begin{array}{c}2,30 \\
(974 / \mathrm{Nen})\end{array}$ & $\begin{array}{c}1,56 \\
(1533 / \mathrm{Nen} .)\end{array}$ & $\begin{array}{c}1,05 \\
(1200 / \text { Chile: } 1700)\end{array}$ \\
\hline $\begin{array}{l}\text { Esperanza de vida } \\
\text { (años) }\end{array}$ & $\begin{array}{c}0,97 \\
\text { (28/Uru.: 49) }\end{array}$ & $\begin{array}{c}0,86 \\
(32 / \mathrm{Arg} .: 53)\end{array}$ & $\begin{array}{c}1,09 \\
\text { (51/Uru.: 66) }\end{array}$ & $\begin{array}{c}1,06 \\
(68 / \text { Cuba: } 74)\end{array}$ & $\begin{array}{c}1,03 \\
(70 / \text { Cos.: } 77)\end{array}$ \\
\hline Alfabetización (\%). & $\begin{array}{c}0,79 \\
\text { (28/Uru.: 59) }\end{array}$ & $\begin{array}{c}0,78 \\
\text { (36/Uru.: 76) }\end{array}$ & $\begin{array}{c}0,88 \\
\text { (51/Arg.: } 88)\end{array}$ & $\begin{array}{c}1,06 \\
\text { (84/Uru.: } 95)\end{array}$ & $\begin{array}{c}1,05 \\
\text { (90/Uru.: 97) }\end{array}$ \\
\hline Urbanización $(\%)$... & $\begin{array}{c}\text { n. d. } \\
\text { (10/Arg.: 40) }\end{array}$ & $\begin{array}{c}1.0 \\
(22 / \operatorname{Arg}: 50)\end{array}$ & $\begin{array}{c}1,24 \\
\text { (31/Uru.: } 56)\end{array}$ & $\begin{array}{c}1,40 \\
(70,2 / \operatorname{Arg}:: 70,7)\end{array}$ & $\begin{array}{c}1,32 \\
\text { (74/Arg.: } 76)\end{array}$ \\
\hline $\begin{array}{l}\text { Crecimiento pobla- } \\
\text { cional .................. }\end{array}$ & $\begin{array}{c}0,53 \\
(1,0 / \operatorname{Arg} .: 3,8)\end{array}$ & $\begin{array}{c}0,5 \\
(0,9 / \text { Arg.: } 3,1)\end{array}$ & $\begin{array}{c}1,0 \\
(2,2 / \mathrm{Pan} .: 2,8)\end{array}$ & $\begin{array}{c}1,35 \\
(3,7 / \text { Ven. })\end{array}$ & $\begin{array}{c}1,31 \\
(2,4 / \operatorname{Par}: 3,3)\end{array}$ \\
\hline $\begin{array}{l}\text { Concentración ex- } \\
\text { portaciones........ }\end{array}$ & $\begin{array}{c}0,94 \\
\text { (47/Chile: } 67)\end{array}$ & $\begin{array}{c}1,44 \\
\text { (83/Bol.: } 84,1)\end{array}$ & $\begin{array}{c}1,63 \\
(94 / \mathrm{Nen} .)\end{array}$ & $\begin{array}{c}1,96 \\
(90 / \mathrm{Nen} .)\end{array}$ & $\begin{array}{c}2,65 \\
(75 \mathrm{Nen})\end{array}$ \\
\hline $\begin{array}{l}\text { Capacidad impor- } \\
\text { tadora }\end{array}$ & $\begin{array}{c}0,61 \\
\text { (14/Cuba: 123) }\end{array}$ & $\begin{array}{c}1,18 \\
\text { (39/Uru.: } 110)\end{array}$ & $\begin{array}{c}5,28 \\
(243 \text { Nen. })\end{array}$ & $\begin{array}{c}3,90 \\
\text { (303/Nen.) }\end{array}$ & $\begin{array}{c}1,86 \\
\text { (195/Chile: } 230)\end{array}$ \\
\hline
\end{tabular}

Todas las cifras son promedios de tres años. En los siguientes casos la media de cinco países (Argentina, Brasil, Chile, Colombia y México) se toma como el valor regional: PIB per cápita y esperanza de vida (1900 y 1930), tasa de analfabetismo (1900). Urbanización: promedio simple de la tasa de urbanización por país. Crecimiento poblacional: tasa compuesta anual durante el período comprendido entre la fecha indicada y la precedente, excepto en 1900, donde mide la tasa media entre 1900-1910. Arg.: Argentina; Bol.: Bolivia; Uru.: Uruguay; Cos.: Costa Rica, Par.: Paraguay; Ven.: Venezuela.

FuENTE: Astorga et al. (2002).

medio regional y a una cuarta parte de los argentinos, quienes disfrutaban del valor máximo dentro del grupo (439 dólares).

A comienzos del siglo $\mathrm{xx}$ los indicadores de bienestar de Venezuela están por debajo del promedio regional, lo cual refleja el nivel relativo de atraso del país. En ese momento su nivel de desarrollo se asemejaba al de un país centroamericano con una población algo menor, como Honduras o Guatemala. Por otra parte, el gobierno se financiaba principalmente con los impuestos sobre el comercio (principalmente sobre las importaciones), y el café y el cacao eran los principales productos de exportación. En cuanto al grado de concentración de las exportaciones, el país presentaba valores ligeramente menores que el promedio regional (6 por 100 por debajo) y los dos principales productos de exportación representaban el 47 por 100 del total exportado. El volumen de importaciones per cápita era un 40 por 100 inferior al promedio regional y nueve veces menor que 
el de Cuba, la economía con el mayor nivel de apertura externa en ese momento.

En 1930 el petróleo comienza a mostrar su impacto. El PIB per cápita se cuadruplica (de 106 a 408 dólares), con lo cual el venezolano medio recibe ahora un 50 por 100 más que su equivalente latinoamericano y solamente un 27 por 100 menos que el ciudadano medio argentino. Sin embargo, a estas alturas, todavía la explotación petrolera no se había traducido en una mejora significativa en las condiciones de vida del país, lo cual se evidencia en el retraso relativo de la esperanza de vida y el índice de alfabetización. Si bien es cierto que la educación y la salud habían mejorado, Venezuela avanzaba a un paso más lento que la mayoría de los países de la región. Durante las tres primeras décadas del siglo la población creció con una tasa anual de 0,9 por 100 , la mitad de la tasa latinoamericana, y muy por debajo del valor máximo registrado en Argentina (3,1 por 100). Esto era consecuencia de altos niveles de mortalidad y de un bajo flujo inmigratorio. Mientras tanto, el petróleo se convierte en el primer producto de exportación, lo cual se refleja en el aumento del índice de concentración $(82,6)$. Éste se sitúa a un 44 por 100 sobre el promedio regional y solamente por debajo de Bolivia, donde el estaño daba cuenta de la mayoría de las exportaciones. La capacidad importadora aumenta considerablemente y se sitúa un 18 por 100 por encima del promedio y a menos de tres veces el valor del máximo regional registrado en Uruguay.

A mediados del siglo los indicadores de bienestar de Venezuela comienzan a alcanzar los promedios regionales. Por ejemplo, la esperanza de vida muestra un gran avance. Esto en parte se debió a mejoras significativas en las condiciones de higiene y salud pública (p. ej., erradicación del paludismo), así como también al avance de la medicina en los países desarrollados. El crecimiento poblacional estuvo a la par del promedio regional. El país comenzó a crecer y a ser foco de atracción de la emigración europea. A pesar del rápido aumento de la población, el producto per cápita se duplica, y más, en veinte años (de 408 a 974 dólares), alcanzando el valor máximo regional (2,3 veces sobre el promedio). Si en 1930 el nivel de urbanización estaba cerca del promedio, los años cincuenta dan cuenta de un proceso acelerado de concentración de la población en ciudades. Entre 1930 y 1950 el nivel de importaciones per cápita se incrementa seis veces y, en términos relativos, Venezuela alcanza unos niveles muy por encima del resto de la región. Como veremos más adelante, esto también es reflejo de la disminución del comercio exterior en cierto número de países como consecuencia de la respuesta a la depresión de 1929. En 
cuanto a la concentración de exportaciones, se afianza la tendencia monoproductora; y con la reforma de la ley de hidrocarburos de 1943 y la introducción de la ley del impuesto sobre la renta en 1942, los impuestos a la actividad petrolera se convierten en la primera fuente de ingresos fiscales aportando 60 por 100 del total en 1950 (OCEPRE, 1989). Se acentúa así la doble dependencia del petróleo, fiscal y externa, que será un rasgo característico del resto del siglo.

Al llegar 1980, los niveles de bienestar del país seguían mejorando a un ritmo superior al promedio. El índice de alfabetización es el indicador que muestra una mayor mejoría respecto a los valores de 1950. El aumento de precios del petróleo a comienzos de los años ochenta hace que el PIB per cápita y la capacidad importadora alcancen sus valores máximos históricos. La bonanza petrolera debido al alza súbita de precios representó un aumento sin precedentes del ingreso fiscal ${ }^{2}$. Sin embargo, a pesar de estos avances, la economía daba muestras de estancamiento y presentaba una extrema dependencia de los ingresos petroleros que lo hacian altamente vulnerable a cambios externos. Esto se haría evidente con el estallido de la crisis de la deuda en 1983 y el colapso de los precios del petróleo en 1986. En ese año, el petróleo venezolano se cotizó, en promedio, a 11 dólares por barril, menos de la mitad del precio promedio de 1985. Durante la década de los años noventa el precio del petróleo se mantuvo bajo, en 14 dólares por barril -en términos reales, 41 por 100 por debajo del valor alcanzado durante los años setenta-. En cuanto a los aspectos demográficos y migratorios se acentuaban tendencias extremas. Entre 1950 y 1980 el número de venezolanos creció a una tasa anual de 3,7 por 100, casi el doble que la registrada en el período 1930-1950 y la mayor registrada en la región. A esto hay que añadir una urbanización a ritmo vertiginoso. Mientras en 1960 el porcentaje de población urbana era similar al de la población rural, en 1980 el 70,2 por 100 de la población venezolana se concentraba en ciudades. El índice de urbanización del país en 1980 superaba al promedio regional en 40 por 100 y era sólo superado por el de Argentina. La velocidad con que se sucedieron las transformaciones internas en Venezuela ha hecho difícil lograr un proceso de desarrollo más ordenado y armonioso. Además, las demandas de educación, salud y vivienda se multiplicaron al tiempo que los recursos petroleros se estancaron.

${ }^{2}$ En los diez años transcurridos entre 1974 y 1982 los ingresos fiscales alcanzaron un total de 131,5 billones de bolívares a precios de 2001, una cantidad 1,5 veces superior a los ingresos percibidos durante el período 1924-1974 (López y Rodríguez, 2001). 
El final del siglo xx está dominado por dos rasgos: la vuelta al promedio de los indicadores de bienestar y la ausencia de cambios significativos en la vulnerabilidad externa y fiscal. Sin duda, el cambio más notable lo constituye el descalabro del PIB per cápita. Éste, en términos absolutos, muestra un retroceso a los niveles alcanzados en 1950 y una caída del 50 por 100 en relación con el promedio regional ${ }^{3}$. Las causas inmediatas de este resultado son la caída en los precios del petróleo y el alto crecimiento poblacional en las tres décadas precedentes. En un análisis más profundo, apunta al fracaso en hacer perdurable la riqueza petrolera mediante la diversificación económica, debido a las ineficiencias en el proceso de acumulación de capital, tanto físico como humano. La productividad de la economía se estancó durante las dos últimas décadas del siglo $\mathrm{xx}$, mostrando uno de los peores resultados en la región ${ }^{4}$. Por otro lado, en momentos en que América Latina avanza en un proceso claro de diversificación de las exportaciones, el país aún mantiene un alto grado de concentración de sus exportaciones que lo hacen sumamente vulnerable a cambios súbitos en el mercado petrolero. Uno de los factores de mayor peso para explicar las diferencias en la estructura económica de los países, así como en los resultados obtenidos, es la naturaleza del sector exportador y su vinculación con el resto de la economía. Éste es el tema del cual nos ocuparemos a continuación.

\section{LA LOTERÍA DE LAS MATERIAS PRIMAS}

Carlos Díaz Alejandro acuñó el término «lotería de los productos primarios» para sintetizar las implicaciones que el tipo de bien exportado tiene para el desarrollo de los países. La lotería es el resultado de la combinación y confluencia de varios elementos. En primer lugar, el azar determina el potencial del país en términos de recursos naturales. Este potencial se manifiesta de diversas maneras: ricos yacimientos minerales, como estaño en Bolivia y cobre en Chile, o naturales, como el guano en Perú y el caucho en la Amazonía; condiciones naturales favorables para la introducción y cultivo de ciertos frutos, como el café en Brasil y la caña de azúcar

${ }^{3}$ Astorga et al. (2003a) ofrece un análisis de la evolución del nivel de vida en América Latina en el siglo xx.

${ }^{4}$ Durante ese periodo productividad total de ios factores cayó a una tasa anual de 3,3 por 100 , el peor resultado entre las economías grandes y medianas de América Latina (Astorga et al., 2003b). 
en Cuba; o una posición geográfica con valor económico, como en el caso de Panamá. Las características del producto condicionan el origen del capital y definen la manera de vincularse la actividad exportadora con la economía interna mediante los encadenamientos directos e indirectos (Hirschman, 1957 y 1981). Finalmente, las condiciones de la demanda internacional y los cambios tecnológicos determinan la estabilidad, cuantía y permanencia de los ingresos de exportación. A continuación estudiaremos estos elementos con mayor detalle.

\section{Vínculos del sector exportador con la economía interna}

Los encadenamientos directos se refieren a la capacidad del sector exportador para estimular el desarrollo de otras actividades mediante la demanda de insumos y maquinaria o el procesamiento del bien exportado. Por otra parte, los encadenamientos indirectos (p. ej., a través del gasto fiscal) tienen que ver con los efectos sobre la demanda agregada y la capacidad para generar divisas. La generación de divisas permite el funcionamiento del resto de la economía interna al hacer posible la importación de insumos y bienes de capital. Es así como, a través de los encadenamientos, directos e indirectos, los cambios en el volumen y precio del producto de exportación afectan al nivel de actividad de la economía interna.

En el caso del petróleo, las actividades de exploración y la instalación de la infraestructura requerida para su explotación y transporte, por lo general, dan lugar a encadenamientos directos importantes en las etapas iniciales del desarrollo de la industria extractiva. Pero una vez que ésta está instalada, la demanda interna de insumos disminuye considerablemente. En consecuencia, las actividades asociadas con el procesamiento aguas abajo del petróleo crudo (p. ej., refinación y petroquímica) son las llamadas a reforzar los vínculos directos con el resto de la economía. Sin embargo, en la medida en que estas actividades tiendan a hacerse fuera del país, la industria petrolera adquiere las características de un enclave. En ese caso, su principal contribución se da mediante los encadenamientos indirectos, por ejemplo, divisas e impuestos. Otra implicación económica de la explotación del petróleo es que ésta tiende a estar en manos del capital extranjero. Esto se debe a la presencia de altos riesgos durante la etapa de exploración de yacimientos y a la alta intensidad de capital requerida en su explotación. Las compañías transnacionales están en mejores condiciones para diversificar los riesgos de exploración debido a su capacidad 
para operar en diferentes países. Así, la posible pérdida financiera ocasionada por la falta de éxito en encontrar petróleo en una región en particular, puede ser compensada con un hallazgo importante en otra. Además, la cuantía en la inversión inicial requerida pone en desventaja al capital nacional, sobre todo en países en vías de desarrollo.

Las implicaciones de un producto mineral como el petróleo contrastan con un producto agrícola como el café. El café ha dominado la actividad económica de un número de economías en la región a lo largo del siglo y su exportación ha representado la principal fuente de estímulo de la actividad productiva interna ${ }^{5}$. Éste es el caso de Brasil, Colombia, Costa Rica y Guatemala durante el siglo xx y de Venezuela hasta los años veinte. En contraste con la extracción minera, el cultivo del café no requiere una tecnología avanzada ni una inversión inicial cuantiosa o de alto riesgo. Esto permite que su producción esté en manos del capital local. Además, el procesamiento del café es intensivo en el uso de mano de obra y, por lo general, se lleva a cabo en el país de origen, lo cual provee un encadenamiento directo importante en términos de empleo.

\section{Las bonanzas y el modelo del síndrome holandés}

Una vez que el elemento temporal entra en juego se abre la posibilidad de un aumento súbito de los ingresos de exportación. El modelo del síndrome holandés es una herramienta útil para el análisis de los efectos de las bonanzas exportadoras ${ }^{6}$. El modelo predice que un choque externo positivo tiene dos implicaciones para la economía interna. En primer lugar, cuando el ingreso de la bonanza es gastado internamente, el precio de los bienes no comerciables tiende a subir en relación con el precio de los bienes comerciables ${ }^{7}$. Este movimiento al alza en los precios relativos se conoce con el nombre de apreciación del tipo de cambio real. De acuerdo con el modelo, el bienestar aumenta en el nuevo equilibrio, pero a costa

${ }^{5}$ Véase Thorp (1991) para una comparación interesante entre las consecuencias para el desarrollo económico de la minería en Perú y del café en Colombia.

${ }^{6}$ Las referencias básicas sobre el modelo de enfermedad holandesa son Corden y Neary (1982) y Corden (1984). Un análisis temprano del síndrome holandés en Venezuela se encuentra en Peltzer (1944).

${ }^{7}$ Los bienes comerciables son aquellos que están expuestos a la competencia externa (p. ej., manufacturas). Por otro lado, los bienes no comerciables son aquellos cuyo precio está dado por las condiciones de oferta y demanda locales, como en el caso de los servicios de peluquería. 
de una reasignación de recursos a favor de los sectores productores de bienes no comerciables y en contra de los sectores productores de bienes comerciables. En la medida en que el gasto tenga un alto componente importado o se destine a la inversión y la ampliación de la capacidad productiva, el impacto de la apreciación del tipo de cambio real en el sector de bienes comerciables será menor. En segundo lugar, el producto marginal del trabajo aumenta en aquellos sectores que experimentan incremento súbito de ingresos, así como también su demanda de mano de obra. Esto trae como resultado un desplazamiento de trabajadores desde el resto de la economía hacia ese sector $^{8}$. Por otra parte, el impacto de la bonanza en el sector exportador sobre las actividades vinculadas a la producción de bienes comerciables depende, en parte, del nivel de desarrollo de la economía interna. En una economía con un bajo nivel de desarrollo industrial, la apreciación del tipo de cambio real tiene su efecto principal en la competitividad externa del sector agrícola. En este caso, el cambio en los precios relativos, al abaratar el costo de los bienes importados, tiende a inhibir, antes que destruir, el desarrollo del sector manufacturero.

Bajo la óptica del modelo del síndrome holandés, el impacto de la bonanza petrolera en Venezuela se puede dividir en dos etapas. Durante la fase de instalación y consolidación de la industria petrolera (1910-1943) prevaleció el efecto de movimiento de recursos, que se tradujo en un aumento significativo en la demanda de mano de obra y otros insumos productivos. El efecto de los encadenamientos hacia atrás fue importante, sobre todo en lo relativo a la construcción de vías de comunicación y la provisión de servicios en aquellas áreas cercanas a los pozos que, por lo general, estaban poco desarrolladas para ese momento (Bell, 1922). El efecto del gasto predominó después de la Segunda Guerra Mundial. Para ese entonces, la industria petrolera había alcanzado ya un nivel de madurez relativa y el Estado venezolano aumentaba considerablemente su participación de los ingresos petroleros tras la aprobación de una nueva Ley de Hidrocarburos en 1943 (Machado, 1990). A partir de ese momento, la principal contribución del petróleo se dio a través de los encadenamientos indirectos asociados con el gasto público.

Como veremos más adelante, a partir de comienzos de los años sesenta Venezuela evitó el efecto anticonceptivo del ingreso petrolero en el desarrollo del potencial manufacturero mediante una política de protección y estí-

${ }^{8}$ A este fenómeno se le conoce en la literatura especializada con el nombre de efecto movimiento de recursos. 
mulo a tales actividades. Por otro lado, la presión al alza en los precios relativos - a favor de los bienes no comerciables- fue en parte frenada por un alto componente del gasto destinado a importaciones y una política activa de inmigración que alivió la demanda de mano de obra. La apreciación del tipo de cambio real se dejo sentir en los años que siguieron al incremento súbito de los precios del petróleo en 1973, si bien resalta por lo modesto de la apreciación real dada la magnitud del incremento en el gasto público (Hausmann, 1989). El sector más afectado después de 1930 fue la agricultura de exportación que dejó de ser competitiva en el exterior debido al encarecimiento de sus insumos, si bien encontró en el aumento de la demanda interna un paliativo al estrago causado por la aparición de la industria petrolera.

\section{PARALELISMOS Y COMPARACIONES CON OTRAS BONANZAS}

¿En qué medida la lotería de los productos primarios produjo diferentes resultados en Venezuela?, ¿ganó el país un premio único? Para responder estas preguntas observaremos algunos indicadores cuantitativos y la experiencia de otras bonanzas en la región. Comenzaremos con el auge del caucho amazónico. Luego centraremos la atención en la experiencia chilena, primero con el salitre a finales del siglo XIX y comienzos del $\mathrm{xx} y$, luego, con la exportación en gran escala del cobre después de los años veinte.

\section{La fiebre del caucho ${ }^{9}$}

La bonanza del caucho del Amazonas fue la última gran bonanza del siglo $\mathrm{xx}$ y la primera del siglo Xx. Éste es un ejemplo típico de un auge efímero basado en la explotación de un producto renovable. Entre 1860 y 1910 la selva amazónica suplió un porcentaje superior al 60 por 100 de la producción mundial de caucho natural. Todos los países cuyos territorios incluyen parte de la cuenca amazónica participaron, en mayor o en menor grado, de ese auge. En particular, Brasil y Perú fueron los principales beneficiarios, siendo Manaos e Iquitos las principales ciudades que experimentaron la efervescencia y riqueza efímera de dicha bonanza. Venezuela se benefició sólo marginalmente. La extracción del caucho generó

\footnotetext{
${ }^{9}$ Esta sección se basa en Barham y Coomes (1995).
} 
una expansión económica sin precedentes. Por ejemplo, el ingreso per cápita en la región amazónica de Brasil se incrementó en un 800 por 100 , mientras que la población de la zona cauchera creció en más de 400 por 100 , lo cual se reflejó en la multiplicación de pueblos y ciudades a lo largo del Amazonas. Sin embargo, la prosperidad llegó a su fin en la segunda década del siglo xx cuando la producción de menor costo de las plantaciones británicas en Asia inundó el mercado. Ya para comienzos de los años veinte, en momentos en que Venezuela comenzaba a recibir el impacto de la explotación petrolera a gran escala, la bonanza del caucho habia terminado si dejar un rastro perdurable. Evidencia de ello es que en la Amazonía brasileña el ingreso per cápita había retrocedido a los niveles que tenía con anterioridad al auge. El foco de la inversión en infraestructura fue en obras destinadas a mejorar los vínculos entre las zonas productoras y los mercados internacionales. Así, la acción del Estado tendió a reforzar la lógica del sector privado. La explotación del caucho generó pocos encadenamientos directos. La bonanza produjo un cambio en los precios relativos que benefició las actividades no comerciables (construcción, bienes raíces y servicios) cuyo dinamismo dependía directamente de los ingresos del caucho. De la misma manera, la viabilidad de las pocas industrias sustitutivas de importaciones que surgieron también estaba supeditada a tales ingresos. Por otra parte, si bien la agricultura fue una fuente de crecimiento durante la bonanza, su potencial encontró limitaciones en el nivel bajo de inversión y problemas de eficiencia de la tierra. El legado principal de esta bonanza fue la creación de centros urbanos de importancia y el establecimiento de una firme presencia del Estado en la cuenca amazónica.

\section{El salitre y el cobre chilenos ${ }^{10}$}

Con la anexión de los territorios ricos en salitre de Perú y Bolivia a raíz de la guerra del Pacífico (1879-1881), Chile se convirtió súbitamente en el principal productor de ese bien (la lotería en este caso consistió en ganar la guerra). El salitre tenía gran demanda internacional como insumo esencial para la industria de explosivos y como fertilizante en los países más desarrollados. La importancia económica que tuvo este producto para la economía chilena se puede observar en el cuadro 2. Para el período 1900-1920 el salitre representaba entre el 65 y el 80 por 100 del total

"i" Esta sección se basa en Palma (1999) y Meller (1990). 
CUADRO 2

Contribución de varios productos primarios en Chile y Venezuela

\begin{tabular}{|c|c|c|c|c|}
\hline & \multicolumn{2}{|c|}{ Cbile } & \multicolumn{2}{|c|}{ Venezuela } \\
\hline & Salitre & Cobre & Café & Petróleo \\
\hline Participación .................. & $(1900-1925)$ & $(1940-1980)$ & $(1900-1925)$ & $(1925-2000)$ \\
\hline \% Total X..................... & $65-80$ & $50-70$ & $45-55$ & $80-90$ \\
\hline$\%$ X/PIB ..... & $25-30$ & $7-9$ & $15-18$ & $20-25$ \\
\hline \% Fiscal...................... & $45-53$ & $15-30$ & n. a. & $60-80^{a}$ \\
\hline Cuantía ........................... & 30 & 56 & 9 & 180 \\
\hline Duración (años; inicio). & $(45 ; 1879)$ & $(40 ; 1940)$ & $(55 ; 1870)$ & $(75 ; 1925)$ \\
\hline
\end{tabular}

Total X: participación en el total exportado; X/PIB: participación de las exportaciones del producto en el PIB. Fiscal: participación directa en el ingreso público. Cuantía: promedio anual de la contribución de las exportaciones del producto para el pago de importaciones per cápita (en dólares de 1970) en el período. Se obtiene al multiplicar la participación del producto en auge en el total exportado por las importaciones per cápita en términos reales. Duración: lapso durante el cual el producto representó al menos el 50 por 100 del total exportado, seguido por el primer año en el que se alcanza dicho porcentaje.

a Después de 1943.

FunNTEs: salitre y cobre, Meller (1990) y Thorp (1998); café y petróleo (Baptista, 1996).

exportado, las exportaciones daban cuenta entre un 25 y 35 por 100 del producto interno bruto y su contribución impositiva varió entre el $45 \mathrm{y}$ el 53 por 100. Desde el comienzo de la bonanza salitrera, dada la certidumbre de su carácter efímero, hubo claridad y consenso en cuanto a su destino. El producto de los derechos de exportación del salitre se destinaría en gran parte al financiamiento de inversión en obras públicas y en educación. De esta manera, una vez agotada esta fuente de riqueza, Chile podría contar con una fuente alterna de riqueza estable para sustituir al salitre.

Sin embargo, la preponderancia del salitre como principal producto de exportación y fuente de ingresos fiscales introdujo un elemento de alta vulnerabilidad en la economía chilena. Esto se haría evidente en los años veinte cuando el salitre natural fue rápidamente desplazado por un sustituto sintético a raíz de la introducción de una serie de innovaciones tecnológicas que redujeron considerablemente los costos de producçión de este último. Sin embargo, lo que la lotería de los productos primarios le quitó a Chile con el salitre. se lo dio con el cobre. En momentos en que el salitre natural era desplazado por el sintético, otra serie de cambios tecnológicos posi- 
bilitaron la explotación a gran escala de mineral de cobre de baja ley, recurso del cual Chile poseía una de las mayores reservas del mundo. De esta manera, el cobre se convirtió en los años treinta en el principal producto de exportación. Al igual que con el salitre, la producción en gran escala del cobre estuvo en manos del capital extranjero. Su explotación requería una inversión considerable y una tecnología de la que carecían los empresarios locales. De nuevo Chile adquirió una alta dependencia en la exportación de un solo producto (el cobre representó alrededor del 60 por 100 del total exportado durante el período 1940-1980), y pronto, al igual que en Venezuela, la pugna por las ganancias entre las empresas trasnacionales y el estado se convirtió en el centro de la acción pública. Durante la fase inicial de la explotación del cobre a gran escala los impuestos a esa actividad se mantuvieron muy bajos. Sin embargo, en la década de los años cincuenta el impuesto promedio representaba el 38 por 100 (Meller, 1990). Por otra parte, cuando se compara con el salitre, la contribución del cobre en el PIB durante el período 1940-1980 fue relativamente baja (7-9 por 100). Esto es en parte consecuencia del mayor grado de desarrollo de la economía interna, resultado del proceso de industrialización acelerada que tuvo lugar en el período.

Si bien la presencia del petróleo en Venezuela resalta por su importancia, cuantía y duración, no se puede concluir que haya sido una excepción en la región. Quizás su paralelo más cercano se encuentre en el salitre. En ambos casos la importancia del producto creó una doble dependencia, externa y fiscal, marcada. Sin embargo, a diferencia del salitre, el petróleo ha tenido la suerte de no haber enfrentado sustitutos de importancia, y el país ha tenido la «suerte» de lo generoso y prolongado de esa lotería. No obstante, la doble dependencia ha colocado a la economía venezolana en una situación de alta vulnerabilidad a cambios en el mercado petrolero internacional, cuyas consecuencias han sido sentidas sobre todo después de 1986. En relación con la cuantía de la bonanza ${ }^{\text {"1 }}$, la era petrolera en Venezuela muestra cifras extraordinarias: tres veces la cuantía del cobre en Chile y seis veces la del salitre. Pocos productos se acercan a los valores alcanzados por el petróleo. Uno de ellos es el azúcar en Cuba alrededor

1 La cuantia resulta de multiplicar la participación del producto en auge en el total exportado por las importaciones per cápita en términos reales. Esta medida se acerca más al valor retenido de la bonanza en el país productor. Una medición de la cuantía en términos del valor de las exportaciones, al no ajustar por las ganancias expatriadas, sobrestima la contribución del producto de exportación. El sesgo es especialmente relevante en el caso de la exportación minera durante la primera mitad del siglo. 
de 1920, cuando representó 160 dólares de importaciones per cápita (a precios de 1970). Una comparación más general arroja el mismo resultado. Durante el periodo 1940-1980 el promedio anual de las importaciones de Venezuela representó el 15 por 100 del total correspondiente a Latinoamérica, más de cuatro veces por encima de su contribución en la población total (3,6 por 100). Mientras que en Chile, en el pico de la exportación salitrera, alrededor de 1910 , las importaciones representaron el 10 por 100 del total de la región, un poco más de dos veces el peso en la población $(4,7 \text { por } 100)^{12}$. El único país en alcanzar una participación semejante en las importaciones regionales fue Cuba a comienzos de siglo cuando las importaciones dieron cuenta del 15 por 100 del total regional, cinco veces mayor que su participación en la población (2,6 por 100). La información presentada en el cuadro 2 también permite comparar la contribución del café y el petróleo en Venezuela. Aparte de las diferencias cualitativas entre estos dos productos ya señaladas (escala de producción, origen del capital y naturaleza de los encadenamientos), los indicadores cuantitativos muestran una diferencia significativa en cuanto a la participación del producto, sobre todo en el peso en el total exportado y la contribución fiscal. El petróleo duplica la importancia relativa del café en el país. Y el contraste es aún mayor en lo referente a la cuantía de recursos generados. El petróleo registra un valor 20 veces mayor que el asociado a las exportaciones de café.

\section{Estabilidad de los ingresos externos}

Otro aspecto a considerar en las implicaciones de los productos primarios es la estabilidad de los ingresos de exportación. Los cambios en los ingresos del principal producto de exportación pueden responder a las variaciones de volumen o de precio. A continuación centraremos nuestra atención en las variaciones de precio. Los cambios en el volumen de extracción petrolera han sido más bien graduales, producto de la expansión paulatina de la capacidad productiva durante la etapa de consolidación de la industria petrolera y, más recientemente, debido a los recortes de producción asociados con las políticas de defensa de los precios puestas en

${ }^{12}$ Cálculos propios a partir de cifras en Astorga et al. (2002). 
práctica por la OPEP ${ }^{13}$. Sin embargo, la volatilidad en los precios ha sido mucho mayor, sobre todo con posterioridad a 1970. Esto ha significado un incremento sustancial en la complejidad de la conducción de la política económica, sobre todo en cuanto a cómo estabilizar el gasto público ante un ingreso altamente aleatorio. El cuadro 3 incluye información sobre la volatilidad del precio de un conjunto de materias primas que han dominado las exportaciones de la región. En la primera línea se mencionan, en orden de importancia, aquellos países que han sido productores mayores durante el siglo. Luego se identifican cinco períodos donde los años límites son el comienzo y final del siglo xx, el comienzo de la Gran Depresión y la antesala al aumento de los precios del petróleo en los años setenta.

\section{CUADRO 3}

Volatilidad precio de los principales bienes de exportación

\begin{tabular}{ccccccc}
\hline \multirow{2}{*}{$\begin{array}{c}\text { Paises } \\
\text { productores }\end{array}$} & Azúcar & Café & Cacao & Cobre & Estaño & Petróleo \\
\cline { 2 - 6 } & $\begin{array}{c}\text { Cuba, Bra. } \\
\text { Dom., Haiti }\end{array}$ & $\begin{array}{c}\text { Bra., Col., } \\
\text { Cos., Gua., } \\
\text { Venezuela }\end{array}$ & Ecuador & Chile, Perú & Bolivia & $\begin{array}{c}\text { Venezuela, } \\
\text { México, } \\
\text { Ecuador }\end{array}$ \\
\hline $1900-1930 \ldots$ & 34,2 & 26,6 & 21,4 & 20,0 & 19,6 & 26,0 \\
$1930-1970 \ldots$ & 40,1 & 21,2 & 36,4 & 21,0 & 19,5 & 14,5 \\
$1970-2000 \ldots$ & 49,1 & 29,2 & 35,1 & 21,6 & 20,1 & 29,6 \\
$1900-1970 \ldots$ & 37,6 & 23,5 & 31,1 & 20,0 & 19,1 & 20,2 \\
$1900-2000 \ldots$ & 45,2 & 28,4 & 32,3 & 21,0 & 19,7 & 28,4 \\
\hline
\end{tabular}

Volatilidad: desviación típica de la tasa anual promedio de crecimiento del precio del bien de exportación. Abreviaturas: Bol.: Bolivia; Bra.: Brasil; Col.: Colombia; Cos.: Costa Rica; Dom.: Republica Dominicana; Gua.: Guatemala.

FuENTE: Astorga et al. (2002).

La inestabilidad introducida por las fluctuaciones de precios en los mercados externos fue un rasgo común en la mayoría de los productos exportados por Latinoamérica. Sin embargo, el petróleo aparece como uno de los productos de menor volatilidad en su precio, en especial durante

${ }^{13}$ En los años veinte ocurrió un incremento inmenso en el volumen de producción que convirtió al país en el primer exportador mundial de petróleo. Luego la producción se estabilizó gradualmente y osciló sobre los 3 millones de barriles diarios entre 1955 y 1975 —año de la nacionalización de la industria petrolera (Baptista, 1996) - . Durante el período 1976-2000 la producción promedio osciló sobre los 2 millones de barriles diarios. 
el período 1930-1970. Por otra parte, el precio del azúcar es el de mayor volatilidad, tanto en los subperíodos como para el siglo completo, lo cual tuvo consecuencias muy negativas para las economías dependientes de ese producto, como la cubana. El café y el cacao también presentan un alto nivel de fluctuaciones en su precio. Durante gran parte del siglo xx Venezuela fue afortunada en términos de fluctuaciones en el precio del principal producto de exportación. La volatilidad ha cobrado importancia durante las últimas tres décadas. Una de las principales consecuencias de dicha volatilidad se ha manifestado en una mayor complejidad en la conducción de la política económica del país. Las alzas de precios del crudo en 1973 y a principio de los años ochenta, llevaron a pensar que los precios altos perdurarían y, en consecuencia, los gobiernos tendieron a endeudarse y gastar excesivamente. Así, la caída de los precios del crudo en 1986 sorprendió al país y sus gobernantes. Gran parte de los recursos generados por los precios altos se destinaron a financiar grandes proyectos de inversión y a la multiplicación de empresas del Estado, cuya eficiencia y racionalidad económica ha sido cuestionada ${ }^{14}$. Finalmente queremos resaltar el elemento de oportunidad en las bonanzas. En el caso chileno el cobre fue oportuno porque coincidió con el declive del salitre y evitó así mayores ajustes. La aparición del petróleo fue oportuna en otro sentido. Como veremos a continuación, contar con el petróleo fue un factor determinante en el impacto que tuvo en el país una de las grandes conmociones externas que afectaron a la región en el siglo xx: la crisis de 1929.

\section{LOS AÑOS DE LA GRAN DEPRESIÓN}

Las conmociones externas han sido una fuente importante de cambios en los países latinoamericanos. Ellas han representado tanto amenazas como oportunidades ${ }^{15}$. La depresión de los años treinta afectó a los países de la región de manera diferente. En primer lugar, se produjo un cambio

${ }^{14}$ La mayoría de las empresas del Estado tuvieron que ser capitalizadas luego de la crisis de la deuda. Además, un gran número de proyectos de inversión pública arrojaron tasas de retorno por debajo de lo normal y tuvieron que ser subsidiados (Bourguignon, 1988).

${ }^{15}$ Así, por ejemplo, en el lado negativo, caídas en los valores de exportación deprimen la actividad económica y causan un ajuste de importaciones de bienes esenciales. Como aspectos positivos, las guerras aumentan la demanda de productos estratégicos -como el petróleo-y las interrupciones prolongadas del comercio internacional estimulan la crea. ción de nuevas industrias. 
drástico en los términos de intercambio debido a que, por lo general, el precio de las exportaciones disminuyó en mayor medida que el de las importaciones. También se dio una caída, aunque menos severa, en los volúmenes exportados, lo cual, sumado al primer efecto, resultó en el colapso del valor de las exportaciones. Esto último se tradujo en una disminución significativa de las importaciones y del consumo en general (Díaz Alejandro, 1984). Otra de las consecuencias de la crisis fue la interrupción del flujo de capitales hacia Latinoamérica. Durante la década de los años veinte tuvo lugar un aumento considerable de los niveles de endeudamiento externo en la región, lo cual introdujo un elemento adicional de vulnerabilidad. La ausencia de financiamiento externo, sumado a la caída del valor de las exportaciones, hizo difícil el servicio de la deuda externa y varios países se vieron forzados a interrumpir o postergar los pagos. Por otra parte, el aumento en el servicio de la deuda y la disminución de los ingresos provenientes del comercio internacional provocaron una crisis fiscal en un gran número de países.

La crisis del 29 originó una visión pesimista en la mayoría de los gobiernos de la región sobre la conveniencia del modelo exportador. Esto dio paso a una política activa de estímulo a la demanda agregada y de protección a la industria local. La inversión extranjera directa no desapareció, pero en muchos casos cambió su orientación desde los sectores exportadores hacia las industrias sustitutivas de importaciones. Díaz Alejandro (1984) resume la situación general de la siguiente manera:

«El desarrollo latinoamericano experimentó un punto de inflexión durante los años treinta. El contraste entre 'antes y después de 1929' puede que a menudo se exagere, pero no hay duda que la década fue testigo de un cierre de las finanzas y el comercio internacional, y un surgimiento relativo de actividades de sustitución de importaciones, primordial, pero no exclusivamente, en manufactura. Otras tendencias visibles antes de 1929, tales como urbanización y un interés creciente del estado en la promoción del desarrollo económico, continuaron en los treinta y se aceleraron en algunos países. La memoria de los años treinta ha influenciado profundamente la actitud de la región hacia las finanzas y el comercio internacional; los valores de los indicadores per cápita del comercio internacional alcanzados al final de los años veinte no fueron superados en muchas naciones hasta los años sesenta.»

Sin embargo, una mirada a los indicadores del comercio exterior muestra que la experiencia venezolana se desvía de esta generalización. El cuadro 4 ofrece una evaluación comparativa del impacto de la depresión en 


\section{CUADRO 4 \\ El impacto de la Gran Depresión, $1932(1928=100)$}

\begin{tabular}{|c|c|c|c|c|c|}
\hline & $\begin{array}{c}\text { Precios } \\
\text { exportación }\end{array}$ & $\begin{array}{l}\text { Volumen } \\
\text { exportación }\end{array}$ & $\begin{array}{l}\text { Términos } \\
\text { intercambio }\end{array}$ & $\begin{array}{c}\text { Poder } \\
\text { compra } \\
\text { exportación }\end{array}$ & $\begin{array}{l}\text { Principal } \\
\text { producto } \\
\text { (\% total) }\end{array}$ \\
\hline Argentina ........................ & 37 & 88 & 68 & 60 & trigo $(18)$ \\
\hline 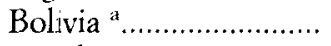 & 79 & 48 & 130 & 60 & estaño (84) \\
\hline Brasil.............................. & 43 & 86 & 65 & 56 & café (68) \\
\hline Chile ................................. & 47 & 31 & 57 & 17 & salitre (43) \\
\hline Colombia ....................... & 48 & 102 & 63 & 65 & café (64) \\
\hline Costa Rica..................... & 54 & 81 & 78 & 65 & café $(67)$ \\
\hline 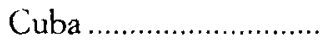 & 37 & 66 & 62 & 49 & azúcar (68) \\
\hline 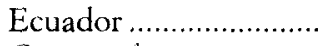 & 51 & 83 & 74 & 60 & cacao (32) \\
\hline Guatemala .................. & 37 & 101 & 54 & 55 & café (74) \\
\hline Honduras......................... & 91 & 101 & 130 & 133 & banano $(50)$ \\
\hline México ....................... & 49 & 58 & 64 & 47 & plata (15) \\
\hline Perú ............................... & 39 & 76 & 62 & 43 & petróleo (33) \\
\hline Venezuela ..................... & 81 & 100 & 101 & 100 & petróleo (82) \\
\hline América Latina ............ & 45 & 78 & 56 & 43 & \\
\hline
\end{tabular}

a $1929=100$.

FUENTES: poder de compra y participación del principal producto para Cuba y Bolivia en Thorp (1998, apen. estadístico). Resto de los paises y variables: Bulmer-Thomas (1994, cuadro 7.2, p. 197).

América Latina basada en la evidencia de un conjunto de índices del comercio exterior; a saber: precio, volumen y poder de compra de las exportaciones, y los términos de intercambio. La última columna presenta el principal producto de exportación alrededor de 1930 y su participación en el total exportado (entre paréntesis). Los índices se construyen con base 100 en el año 1928 (no mostrado en la tabla). Las cifras dan cuenta del valor de los índices para el año 1932 en una muestra de 13 países y del promedio latinoamericano. Así, si tomamos como ejemplo Argentina, el índice del precio de las exportaciones para 1932 es 37, es decir, que los precios cayeron en más del 60 por 100 en comparación con los valores alcanzados en 1928. El índice de volumen (88) muestra que la disminución de la producción exportada no fue tan drástica (12 por 100).

En el cuadro se puede observar cómo en Venezuela durante los primeros años de la depresión, en contraste con la mayoría de los países, no se produjo una caída significativa en los indicadores del comercio exte- 
rior. Si bien es cierto que para 1932 el precio de las exportaciones había caído en un 19 por 100, para ese entonces ya se había recuperado el volumen exportado y su monto se asemejaba al registrado en 1928, ocurriendo lo mismo con los términos de intercambio y el poder adquisitivo de las exportaciones ${ }^{16}$. Estos resultados contrastan con los obtenidos por otros países mineros, como Chile, Bolivia y México, donde la crisis tuvo efectos más marcados. En particular, la economía chilena fue una de las más afectadas. El precio de sus exportaciones (todavía dominadas por el salitre) cayó en más del 50 por 100 y el volumen en casi un 70 por 100 . Esto se reflejó en un colapso del 83 por 100 en la capacidad de compra de las exportaciones, sin parangón en la historia de la región.

Sin duda el petróleo está detrás de estos resultados atípicos. Su mercado fue uno de los primeros en reponerse de la depresión y la baja en el precio fue compensada por una disminución similar en el precio de las importaciones, de manera que su poder de compra se mantuvo constante. Sin embargo, el café y las zonas donde éste se producía en el país no corrieron con la misma suerte ${ }^{17}$. Su exportación se vio afectada por los precios bajos y al aumento de las medidas proteccionistas en los mercados externos tradicionales. Entre 1928 y 1935 el café experimentó una disminución del 50 por 100 en precio de exportación y sólo recuperaría en 1950 niveles similares a los registrados con anterioridad a la crisis. Aunque no se dispone de indicadores cuantitativos a nivel de localidades, los valores de los indicadores para Colombia son ilustrativos del posible impacto de la crisis de 1929 en las zonas cafetaleras venezolanas. También el caso colombiano da una idea de la suerte que podría haber corrido Venezuela si en el momento de la depresión hubiese seguido siendo una economía dominada por el café ${ }^{18}$.

El país no sólo fue la excepción en lo relativo a la intensidad del impacto, sino también en la respuesta del gobierno. Mientras la mayoría de los gobiernos de la región devaluaron sus monedas e implementaron políticas fiscales de corte expansivo, en Venezuela la tesis de la revaluación prevaleció ${ }^{19}$,

16 El poder adquisitivo incluye las importaciones de las compañías y las ganancias retenidas, por lo que no refleja completamente la capacidad de compra de los venezolanos, pero sí es un buen indicador de la tendencia.

17 Para una descripción del impacto de la crisis por regiones véase González Deluca (1994, pp. 218-298). También véase McBeth (1983) para un estudio sobre los efectos sobre la industria petrolera y las zonas cafetaleras.

i* La experiencia colombiana está documentada en Ocampo (1984 y 1999).

19 Entre 1929 y 1932 el bolivar se depreció en un 29 por 100. Después de 1933 la moneda se revalorizó como resultado de la devaluación del dólar y una política cambiaria 
el país acumuló reservas y el gobierno tuvo una situación fiscal predominantemente de superávit. La respuesta de Venezuela se asemeja más a la adoptada por las economías de Centroamérica y el Caribe, las cuales mantuvieron la paridad con el dólar, optaron por el ajuste automático del patrón oro y esperaron la recuperación de los mercados de exportación.

La formulación de la política cambiaria puso de manifiesto la difícil convivencia entre las economías del petróleo y del café. Los intereses vinculados a esta última favorecían una devaluación del bolivar para mejorar su competitividad en los mercados externos, al tiempo que demandaban una ayuda más decidida por parte del gobierno para solventar los problemas financieros del sector causados por la crisis. Por otro lado, la política más apropiada a los intereses del país y del gobierno respecto al petróleo era la opuesta. Con anterioridad a la reforma fiscal de 1942 y la aprobación de la Ley de Hidrocarburos de 1943, la política cambiaria fue uno de los mecanismos principales con los que contaba el gobierno para extraer rentas del negocio petrolero - para ese entonces en manos del capital extranjero-. Debido a que las compañías transnacionales pagaban los salarios y hacian sus compras en bolívares, una revaluación de la moneda automáticamente aumentaba la cantidad de dólares que dejaban en el país. Mientras tanto, con el objetivo de proteger a los exportadores de café de las consecuencias de un bolívar fuerte, el gobierno introdujo un tipo de cambio preferencial -conocido como el Convenio Tinoco-. La contracción en la demanda y la tendencia revaluacionista del tipo de cambio también afectaron a la industria manufacturera, pero en este caso el gobierno mostró menos interés en aliviar las dificultades del sector. La industria textil experimentó una caída en su actividad a lo largo de la década de los treinta y enfrentó un aumento de la competencia extranjera, a diferencia de lo ocurrido en la mayoría de los países de la región ${ }^{20}$. Además, la firma del tratado de libre comercio con EEUU en 1939 representó otro obstáculo para el desarrollo de la industria local. Con el tratado se evitaba la imposición de impuestos por parte del gobierno de ese país a las importaciones de petróleo venezolanas, pero a cambio de permitir la libre importación de manufacturas y otros bienes (Machado y Padrón, 1987).

En cuanto a las cuentas del gobierno, la contribución fiscal petróleo y la ausencia de una deuda externa que servir más que compensaron la

que favorecía un bolivar fuerte. Sobre este asunto consúltese Baptista y Mommer (1987), Rangel (1968, pp. 207-227), y Mayobre (1944).

21) La crisis de la industria textil en esos años está documentada en González Deluca (1994) y Karlsson (1975). 
disminución de ingresos provenientes de las aduanas y los impuestos internos. Esto hizo posible evitar una crisis fiscal que era la norma del momento en la región. Luego de disminuir en 1930 en un 12 por 100 en términos reales, los ingresos del gobierno experimentaron una rápida recuperación, sucediéndose superávit fiscales hasta 1936. El déficit registrado en 1930 fue de 50,7 millones de Bs. --el mayor registrado hasta entonces- cuyas causas principales fueron la cancelación de la deuda externa y una baja significativa en la recaudación de impuestos de importación. Sin embargo, en 1934 la recaudación tributaria fue superior en más de un 25 por 100 a la registrada en 1928 (Veloz, 1945).

El gobierno utilizó parte de los recursos provenientes del petróleo para cancelar la totalidad de sus deudas. Así, en 1930, como parte de los actos conmemorativos del centenario de la muerte de Simón Bolívar, se terminó de pagar la deuda externa, para ese entonces de 23,8 millones de Bs. (equivalente a 629.000 dólares) y en 1935 se liquidó el componente interno de la deuda pública (para ese entonces de 20,7 millones de Bs.). Esta situación no puede ser más contrastante con lo que estaba ocurriendo en otros países donde los gobiernos enfrentaban serios problemas para servir sus deudas. Esto se tradujo en un incumplimiento generalizado que comenzó en 1931. Para 1934 sólo Argentina, Haití y la República Dominicana mantenían un servicio normal de sus deudas externas públicas (Díaz Alejandro, 1984) ${ }^{21}$.

A diferencia de lo ocurrido en otros paises, la crisis del 29 en Venezuela no fue un punto de inflexión que marcó el impulso y consolidación del proceso de industrialización mediante la sustitución de importaciones. En parte esto se debió a la ocurrencia previa de un cambio fundamental cuyo origen fue de carácter interno: la transición de modelo de crecimiento basado en la exportación de café a otro centrado en la de petróleo. La crisis externa de los treinta acentuó los efectos de la economía petrolera y aceleró el desvanecimiento de las actividades tradicionales agrícolas de exportación. El petróleo no sólo apaciguó la magnitud del impacto de la crisis en Venezuela, sino que su presencia, junto con las condiciones iniciales (bajo nivel de industrialización y un tamaño reducido del mercado interno), también evitó una respuesta de política económica más activa como la adoptada por otras economías de la región. En consecuencia, el comienzo

${ }^{24}$ Otro aspecto en el cual Venezuela difiere en relación con lo que fue la norma en la región, es que Juan Vicente Gómez fue uno de los pocos gobernantes que sobrevivió los años de la Gran Depresión. 
de los esfuerzos de industrialización liderada por el Estado se pospuso hasta los años que siguieron a la Segunda Guerra Mundial.

\section{LA SIEMBRA DE LO EFÍMERO}

La guerra trajo consigo escasez de importaciones y expuso la vulnerabilidad de Venezuela ante cambios en los mercados externos. Debido al bajo nivel de desarrollo de la industria local, el lado de la oferta, en general, tuvo poca capacidad de reacción, lo cual llevó a una situación de exceso de demanda que creó presiones inflacionarias serias. Si durante la depresión el problema era que no había con qué comprar, debido a la caída en la capacidad de compra de las exportaciones y el impacto recesivo en el sector cafetalero, ahora el problema era que no había qué comprar debido a las limitaciones en la oferta interna y la interrupción del comercio internacional.

El estímulo dado al comercio interregional durante la Segunda Guerra Mundial sirvió como una ocasión para que Venezuela pudiese comparar su nivel de desarrollo industrial con otros países latinoamericanos. En ese momento existía un desarrollo relativamente importante de la industria textil y de refinación de petróleo, así como una industria establecida de alimentos y bebidas. Sin embargo, el sector artesanal comprendía más del 60 por 100 del producto del sector (Córdova, 1963). A pesar de su comienzo tardío, Venezuela pronto comenzó a recortar terreno a un paso apresurado. Una vez ganada la lucha por la renta petrolera, la atención se centró en cómo hacer para que esa riqueza transitoria se convirtiera en algo perdurable. Se dio el consenso en la necesidad de «sembrar el petróleo», por ejemplo, destinar los recursos por él generados hacia el desarrollo de fuentes de producción nacional y transformar el país en una economía moderna (Betancourt, 1967).

La necesidad de la «siembra» de las ganancias del producto de exportación ha sido una preocupación compartida por muchos países de la región, sobre todo en las economías mineras, donde el grueso del ingreso proviene de un producto de naturaleza no renovable. De nuevo la experiencia chilena con el salitre brinda un paralelo interesante para la discusión del caso venezolano. Dada la evidencia clara de lo efímero de los depósitos de salitre (si bien su fin se debió a la aparición de sustitutos), desde muy temprano en la bonaza, el gobierno chileno propuso un plan para «sembrar el salitre»: la inversión de los derechos de exportación de ese producto en obras públi- 
cas, educación e industria, de manera que una vez acabado el salitre el país poseería una fuente productiva alterna y permanente (Palma, 1999). En Venezuela la siembra se efectuó bajo la influencia del modelo de sustitución de importaciones, que para el momento era la norma en la región. En los países de industrialización más temprana — como Argentina, Brasil, Chile, México y Uruguay - el movimiento hacia la sustitución encontró un empuje determinante en la inestabilidad de la economía internacional en el período de entreguerras y en los problemas de la balanza de pagos. En esos países el papel principal de la política económica durante la posguerra respecto a la industrialización fue el de ordenar un proceso que estaba ya en plena evolución (Thorp, 1998). Sin embargo, en Venezuela la sustitución de importaciones obedeció, en gran medida, a una acción planificada con una participación crucial del Estado; sobre todo a partir de los años sesenta.

Si bien durante los años treinta Venezuela se desvió del curso tomado por la mayoría, en las tres décadas que siguieron el rasgo dominante fue la búsqueda del camino que estaba siendo transitado por las economías más avanzadas de la región. Tras su creación en 1948, la Comisión Económica para América Latina (CEPAL) dio el apoyo teórico e institucional al creciente consenso sobre la importancia de la industrialización. A un nivel más instrumental, las respuestas institucionales adoptadas en otros países para la promoción y estímulo a la industria tuvieron una influencia directa en el diseño del organismo de promoción industrial en Venezuela: la Corporación Venezolana de Fomento (CVF). La CVF fue creada en 1946 por la Junta Revolucionaria de Gobierno presidida por Rómulo Betancourt. Su naturaleza, estructura y funcionamiento estuvo altamente influenciada por las experiencias que tuvieron lugar en Chile con la Corporación de Fomento (CORFO), creada en 1939, y en México con la Nacional Financiera fundada en 1934. La Corporación recibió un poder de acción amplio que incluyó la posibilidad de establecer y operar empresas, adquirir acciones en empresas en funcionamiento y ofrecer financiamiento con un límite de 20 años. Durante los primeros años de operaciones la CVF destinó la mayoría de sus recursos a la expansión de la capacidad de producción de alimentos y la generación de energía eléctrica ${ }^{22}$.

22 La CVF tuvo sus orígenes en la Junta para el Desarrollo de la Producción Nacional, creada por el gobierno del General Medina Angarita en 1944. Consúltese Machado y Arenas (1995) sobre la creación de la CVF, y Barrios (1992) para un estudio del desempeño de la CVF. 
Los esfuerzos en el área del desarrollo industrial iniciados en los años cuarenta continuaron a un ritmo acelerado en las décadas siguientes. En el momento en que se realizó el primer censo industrial en 1936, las industrias tradicionales representaban más del 60 por 100 del empleo y del capital total de la manufactura (excluida la refinación) y más de la mitad del producto ${ }^{23}$. Menos de cincuenta años después, esas industrias experimentaron una reducción sustancial en su importancia. En 1981 las industrias tradicionales empleaban menos del 20 por 100 del total, concentraban un valor equivalente del capital, y producían el 27 por 100 del valor agregado. El terreno cedido por estas industrias fue ganado por las industrias intermedias y básicas que florecieron en los años sesenta y setenta. En términos agregados, el PIB venezolano creció a una tasa anual de 7 por 100 en el período 1950-1980 (BCV, 1990b), una de las más altas de la región.

Si bien es cierto que el tamaño reducido del mercado interno y el efecto anticonceptivo del petróleo retardaron el proceso de industrialización en Venezuela, en la segunda mitad del siglo el petróleo se convirtió en el principal elemento dinamizador y fuente de recursos para la industria sustitutiva. La siembra con protección fue la manera de conciliar el desarrollo industrial con la explotación petrolera. Sin embargo, el petróleo aportó un elemento singular en el proceso de industrialización venezolano. La abundancia de los recursos externos disponibles, la alta capacidad importadora y un tipo de cambio fuerte, generaron unos resultados del modelo sustitutivo sui generis: una industria sustitutiva sin sustitución, poco eficiente y altamente dependiente del sector exportador tanto en términos de divisas como de demanda de sus productos (Astorga, 1999).

\section{COMENTARIOS FINALES}

El análisis comparativo con base en un conjunto de indicadores de desarrollo muestra que el país comenzó el siglo xx con un nivel de bienestar muy por debajo del promedio regional. Sin embargo, hacia mediados del siglo, Venezuela ya había alcanzado el nivel de desarrollo promedio de la región y se colocaba entre los países con mayor potencial de crecimiento. En las dos décadas siguientes se hicieron grandes esfuerzos para promover la industrialización y aumentar la diversificación económica. Durante dicho

${ }^{23}$ Sin embargo, en 1936, de los 8.025 establecimientos manufactureros incluidos en el censo, solamente había 160 empresas con más de 20 empleados. 
período la economía experimentó una de las mayores tasas de crecimiento de la región. Sin embargo, la crisis de la deuda a comienzos de los años ochenta marcó el momento de un cambio drástico en la tendencia de los indicadores del país. A ella siguió el colapso de los precios del petróleo en 1986. Desde entonces, el país ha sufrido un deterioro evidente en su economía e instituciones, tanto en términos absolutos como en relación con la región.

Otro aspecto a resaltar del caso venezolano es lo acelerado de los cambios demográficos y migratorios. El crecimiento poblacional ha sido explosivo. En el período 1950-1980 el país triplicó su población, experimentando la mayor tasa anual de crecimiento poblacional de la región (y una de las más altas del mundo). A esto hay que añadir una urbanización a ritmo vertiginoso. Mientras que en 1960 el porcentaje de población urbana asemejaba al de la rural, en 1980 el 70 por 100 de la población estaba concentrada en ciudades. La velocidad con que sucedieron las transformaciones internas en Venezuela ha hecho difícil lograr un proceso de desarrollo más ordenado y armonioso. Además, las demandas de educación, salud y vivienda se multiplicaron al tiempo que los recursos petroleros se estancaron.

El petróleo es, sin lugar a duda, el elemento clave para entender el proceso de trasformación del país y es, en gran medida, el origen de las diferencias con el camino transitado por otros países latinoamericanos, así como de los resultados obtenidos. En el contexto regional, la bonanza petrolera venezolana ha sido extrema en la cuantía de recursos, en su duración y en la dependencia generada. La comparación con bonanzas originadas por el cobre y el salitre en Chile y el caucho en la cuenca amazónica ilustran la importancia relativa de los recursos aportados por la explotación petrolera en Venezuela. Además, la presencia del petróleo también ha sido un factor que ha generado resultados singulares, por ejemplo, en cuanto al impacto y respuesta a la Gran Depresión y las características del proceso de industrialización.

La "siembra" con protección fue la manera de conciliar el desarrollo industrial con la explotación petrolera. Durante las décadas de los sesenta y los setenta, Venezuela experimentó un desarrollo de industrialización acelerado liderado por el Estado, siguiendo el modelo de desarrollo impulsado por la CEPAL. Sin embargo, el petróleo aportó un elemento singular en el proceso de industrialización venezolano. La abundancia de los recursos externos disponibles, la alta capacidad importadora y un tipo de cambio fuerte, generaron unos resultados del modelo sustitutivo sui generis: una industria sustitutiva con un grado muy bajo de sustitución, poco eficiente 
y altamente dependiente del sector exportador, tanto en términos de divisas como de la demanda de sus productos.

La lotería de las materias primas que le ha tocado a Venezuela ha sido un arma de doble filo. Si bien permitió un avance significativo en los indicadores de bienestar, la construcción de infraestructura y el financiamiento de industrias alternativas, tanto sustitutivas como de exportaciones (p. ej., aluminio), al mismo tiempo dio lugar a una economía altamente vulnerable a la suerte del mercado petrolero internacional. Hoy, al igual que hace cincuenta años, el petróleo representa más de un 80 por 100 del valor exportado, alrededor de un 30 por 100 del PIB y cerca de la mitad de los ingresos fiscales. La exposición extrema a las variaciones en el ingreso petrolero ha sido una fuente constante de desajustes en las cuentas externas y fiscales, en especial después de 1982, con un alto costo en términos de crecimiento económico.

Este trabajo se ha centrado en el tema económico. Sin embargo, una cabal comprensión de lo ocurrido en el país tiene que necesariamente tomar en cuenta el tema político. Aunque no es éste el lugar para abordar este tema, ofreceremos algunas ideas a continuación. En la segunda mitad del siglo xx Venezuela ha sido, junto con Costa Rica, una de las democracias más duraderas y, hasta hace una década, estables de la región. Así, durante el periodo 1960-1980, al tiempo que América Latina era sinónima de dictaduras y violaciones de derechos humanos, Venezuela se mantuvo al margen y dio un ejemplo de tolerancia política y continuidad institucional. Durante muchos años los altos ingresos petroleros afianzaron las instituciones democráticas en el país. Prosperidad y libertad caminaban de la mano. Sin embargo, en el período 1968-1989 la combinación de la abundancia de recursos y un sistema político dominado por el clientelismo dio lugar a un estado hipertrofiado y a una sociedad dependiente y buscadora de rentas. La política económica estuvo marcada por los vicios del "cortoplacismo", la corrupción y la ambición de los dos principales partidos políticos de ganar elecciones a cualquier costo. Estos factores han contribuido al estancamiento de la economía y al resurgir reciente de la inestabilidad política en el país.

El petróleo confirió al país una oportunidad única para avanzar en el desarrollo de su capacidad productiva y del bienestar de la población. Sin embargo, la eficiencia de la inversión de los recursos petroleros y su capacidad para generar riqueza independiente de la renta petrolera está en entredicho. Al final del siglo XX el PIB per cápita retrocedió a los niveles alcanzados en 1950 . Hoy el país está sumido en una grave crisis económica 
y de gobernabilidad. Al igual que a comienzos del siglo pasado, Venezuela está en busca de un destino mejor.

\section{BIBLIOGRAFÍA}

Astorgia, P. (1999): «La Industrialización en Venezuela (1936-1983): el problema de la abundancia», en E. Carnenas, R. Thorp, y J. A. OCAMPO (eds.) (1999b), Fondo de Cultura Editorial.

Astorga, P.; Berges, A. R., y Fitzgerald, E. V. K. (2002): The Oxford Latin American Economic History Database (OXLAD), The Latin American Centre of Oxford University (2002), URL: http://www2.qeh.ox.ac.uk/oxlad/.

- (2003a): «The standard of living in Latin America during the twentieth century», Economic History Review (por publicarse).

- (2003b): «Productivity growth in Latin America during the twentieth century» (en proceso de publicación).

Banco Central de Venezuela (1990a): La Economía Contemporánea de Venezuela, Caracas, edición 50 aniversario.

- (1990b): Series Estadisticas de Venezuela, Caracas, edición 50 aniversario. (Véase también en: http://www.bcv.org.ve/cuadros/series/.)

Baptista, A. (1996): Bases Cuantitativas de la Economia Venezolana: 1830-1994, 2." ed., Caracas, Ediciones María di Mase.

Baptista, A., y Mommer, B. (1987): El Petróleo en el Pensamiento Económico Venezolano, Caracas, Ediciones IESA.

Baru lAM, B. L., y COOMES, O. T. (1995): «Reinterpreting the Amazon rubber boom: investment, the state, and Dutch disease», Latin America Research Review, vol. 29, 2.

Barrios, S. (1992): The Modern Interventionist State in Venezuela. The Case of the Venezuelan Development Corporation, Berkeley, University of California. (Versión en castellano: El moderno Estado Intervencionista en Venezuela. El Caso de la Corporación Venezolana de Fomento, Caracas, CENDES, UCV.)

BelL, P. L. (1922): Venezuela: A Commercial and Industrial Handbook, Washington, D. C., US Department of Commerce.

Betancourt, R. (1967): Venezuela, Política y Petróleo, Caracas, Senderos.

Blomstrom, M., y Meller, P. (1990): Trayectorias Divergentes: Comparación de un Siglo de Desarrollo Económico Latinoamericano y Escandinavo, Santiago, CIEPLAN-Hachette.

Bourguignon, F. (1988): «Venezuela: absorption without growth», en A. Gelk, et al., (ed.) (1988): Oil Windfalls, Blessing or Curse? Oxford University Press and the World Bank.

Bulmer-Thomas, V. (1994): The Economic History of Latin America since Independence, Cambridge, Cambridge University Press.

Cardenas, E.; Tiorp, R., y OCAMPo, J. A. (eds.) (1999a): La Era Exportadora: las Economias Latinoamericanas a Finales del Siglo Diecinueve y Comienzos del Veinte, Ciudad de México, Fondo de Cultura Editorial. 
- (1999b): La Industrialización y el Estado en América Latina: La Leyenda Negra de los Años de la Postguera, Ciudad de México, Fondo de Cultura Editorial.

Cokdova, A. (1963): «La estructura económica tradicional y el impacto petrolero en Venezuela», Economia y Ciencias Sociales, núm. 1, Caracas, pp. 7-28.

Corden, W. M. (1984): «Booming sector and Dutch disease economics: survey and consolidation», Oxford Economic Papers, 36/3, pp. 359-80.

CORDEN, W. M., y NeARY, J. P. (1982): «Booming sector and de-industrialisation in an small open economy», Economic Journal, núm. 92, pp. 825-48.

Díz Alejandro, C. (1984): «Latin America in the 1930s», en R. Thorp (ed.) (1984), Basingstoke, Macmillan y St. Antony's College. (Hay una versión en castellano publicada por el Fondo de Cultura Editorial en 1999.)

Gonzalez Deluca, M. E. (1994): Los Comerciantes de Caracas, Caracas, Cámara de Comercio de Caracas.

Hausmann, R. (1989): Shock Externos y Ajuste Macroeconómico, 50. a ed., Caracas, Banco Central de Venezuela.

Hirsciman, A. O. (1957): The Strategy of Economic Development, New Haven, Yale University Press.

- (1981): «A generalized linkage approach to development, with special reference to staples», en Essays in Trespassing: Economics to Politics and Beyond, L. A., California University Press.

KARLSSON, W. (1975): Manufacturing in Venezuela: Studies on Development and Location, Stockholm, Latinamerica Institutet i Stockholm.

López, C., y Ronriguez, F. (2001): «La política fiscal venezolana 1943-2001», en Reporte de Coyuntura Anual 2001, Oficina de Asesoría Económica, Asamblea Nacional de Venezuela.

Machado de ACEDo, C. (1990): La Reforma de la Ley de Hidrocarburos de 1943: un Impulso Hacia la Modernización, Caracas.

Machado de Acedo, C., y Padrón, M. (1987): La Diplomacia de López Contreras y el Tratado de Reciprocidad Comercial con los Estados Unidos, Caracas, Ministerio de Relaciones Exteriores.

MACIIADO DE ACEDO, C., y ARENAS, N. (1995): «La creación de la Corporación Venezolana de Fomento (1946)», CENDES temas para la discusión, núm. 32, Caracas.

Mayobre, J. A. (1944): «La paridad del Bolívar», en Banco Central de Venezuela (1990a), op. cit., vol. I, pp. 43-84.

McBetri, B. S. (1983): Juan Vicente Gómez and the Oil Companies in Venezuela, 1908-1935, Cambridge, CUP.

Meller, P. (1990): «Una perspectiva de largo plazo del desarrollo económico chileno, 1880-1990», en M. Blomstrom y P. MFller (1990), Santiago, CIEPLAN.Hachette.

Naciones Unidas (1955): Foreign Capital in Latin America, New York.

Ocampo, J. A. (1984): «The Colombian economy in the 1930s», en R. THorp (ed.) (1984), Basingstoke, Macmillan y St. Antony's College. (Versión en castellano, América Latina en los Años Treinta, publicada por el Fondo de Cultura Editorial en 1999.)

- (1999): «La economía colombiana durante la etapa exportadora», en E. CÁRDENAS, R. Thorp y J. A. OcAmpo (eds.) (1999a), Fondo de Cultura Editorial. 
OCEPRE (1989): 40 Años de Presupuesto Fiscal, 1948-1988, Ediciones de la OCEPRE.

PAlmA, G. (1999): «La economía chilena desde la guerra del Pacífico a la Gran Depresión», en E. Cardenas, R. Tilorp y J. A. Ocampo (eds.) (1999a), Fondo de Cultura Editorial.

Peltzer, E. (1944): «La industrialización en Venezuela y el alto tipo de cambio del Bolivar», en Banco Central de Venezuela (1990a), op. cit., vol. I, pp. $85-108$.

Ramos, A. (1923): O Cafe, Rio de Janeiro, Pap. Santa Helena.

Ranciel, D. A. (1968): El Proceso del Capitalismo Contemporáneo en Venezuela, Caracas, UCV.

Thorp, R. (ed.) (1984): Latin America in the 1930s: The Role of the Periphery in the World Crisis, Basingstoke, Macmillan y St. Antony's College.

- (1991): Economic Management and Economic Development in Peru and Colombia, Basingstoke, Macmillan for the OECD Development Centre.

- (1998): Progreso, Pobreza y Exclusión: Una Historia Económica de América Latina en el Siglo XX, Washington, Banco Interamericano de Desarrollo.

Veloz, R. (1945): Economia y Finanzas de Venezuela. 1830-1944, Caracas, Impresores Unidos. 